\title{
Toward spatial justice: The spatial equity effects of a toll road in Cape Town, South Africa
}

\author{
Justin van Dijk \\ Stellenbosch University \\ jtvandijk@sun.ac.za \\ Tom de Jong \\ Utrecht University \\ t.dejong@uu.nl
}

\author{
Stephan Krygsman \\ Stellenbosch University \\ skrygsman@sun.ac.za
}

\begin{abstract}
The present study sets out to provide an ex ante insight into the equity effects of a toll charge on the traffic diversions and geographical accessibility of work locations in the Cape Town metropolitan region, South Africa. Based on a static traffic assignment model and aggregate accessibility measures, computed in a GIS environment, the effects of a toll were estimated for different income categories for both a reference scenario and two toll scenarios. The findings indicate that particularly low-income commuters will divert to alternative routes. However, the results also indicate that the introduction of a toll will only have a limited impact on geographical accessibility. Nevertheless, because particularly low-income commuters are likely to divert to alternative routes, a toll should maybe not be levied on the road toward spatial justice without revenue redistribution or additional investment in the public transport system.
\end{abstract}

\section{Article history:}

Received: November 19, 2013

Received in revised form: August

31,2014

Accepted: November 28, 2014

Available online: August 4, 2015

\section{Introduction}

Within the realm of daily life, transport systems provide the physical links that facilitate the innate mobility of the human race (Cresswell 2006; Duyvendak 2011). However, transport systems worldwide are under pressure as demand for road transport is increasing more rapidly than supply of road capacity (Finn 2012). In an attempt to remedy this disequilibrium, and in order to finance new infrastructural developments, countries and cities across the globe have tried to come up with innovative financing arrangements to ensure the economic efficient use of road infrastructure and to secure a sustainable funding source. Road pricing has often been advanced as a solution. Although road-pricing policies have not gained real momentum in the developing world so far, the metropolitan area of Cape Town, South Africa, is on the verge of getting acquainted with them.

South Africa currently faces major problems with funding its national roads. After the recent implementation of a toll in the province of Gauteng, the South African National Road Agency Limited

Copyright 2015 Justin van Dijk, Stephan Krygsman \& Tom de Jong

http://dx.doi.org/10.5198/jtlu.2015.555

ISSN: 1938-7849 | Licensed under the Creative Commons Attribution - Noncommercial License 3.0

The Journal of Transport and Land Use is the official journal of the World Society for Transport and Land Use (WSTLUR) and is published and sponsored by the University of Minnesota Center for Transportation Studies. This paper is also published with sponsorship from WSTLUR and the Institutes of Transportation Studies at the University of California, Davis, and the University of California, Berkeley. 
(SANRAL) $^{1}$ declared in 2008 to impose a toll on parts of the N1 and N2 national roads in the Cape Town metropolitan region as well (Government Gazette 2008; SANRAL 2012); an overview of the roads to be tolled, the major roads and train lines in the region is given in Figure 1. Unlike the situation in Gauteng where the toll revenues are used for improving and maintaining the charged roads, however, it is unclear whether SANRAL intends to invest the toll revenues earned in the Cape Town metropolitan region in the region itself. Moreover, the local government, fearing negative externalities as a consequence of the toll, has decided to take legal action.

The major point of concern of the local government revolves around the question of what distributive implications can be expected. Because the toll roads will extend into an urban area, the local government fears that vehicles will divert to alternative routes. This fear is augmented by the high dependency on road transportation, which is partly inherited from the ethnic and spatial segregation induced by the apartheid regime that led para-transit (minibus taxis in particular) to become the dominant form of public transport (Walters 2008; Lucas 2011). Moreover, because SANRAL may not use the revenues to mitigate possible negative externalities within the region, equity concerns rise: Will the burdens and benefits be equally distributed along economic and spatial lines? Despite the vast number of studies discussing the social distribution of burdens and benefits of road pricing (Teubel 2000; Santos and Rojey 2004; Eliasson and Mattsson 2006; Bureau and Glachant 2008; Levinson 2010), to date no literature has dealt with the distributional consequences of a toll in such an extraordinary situation.

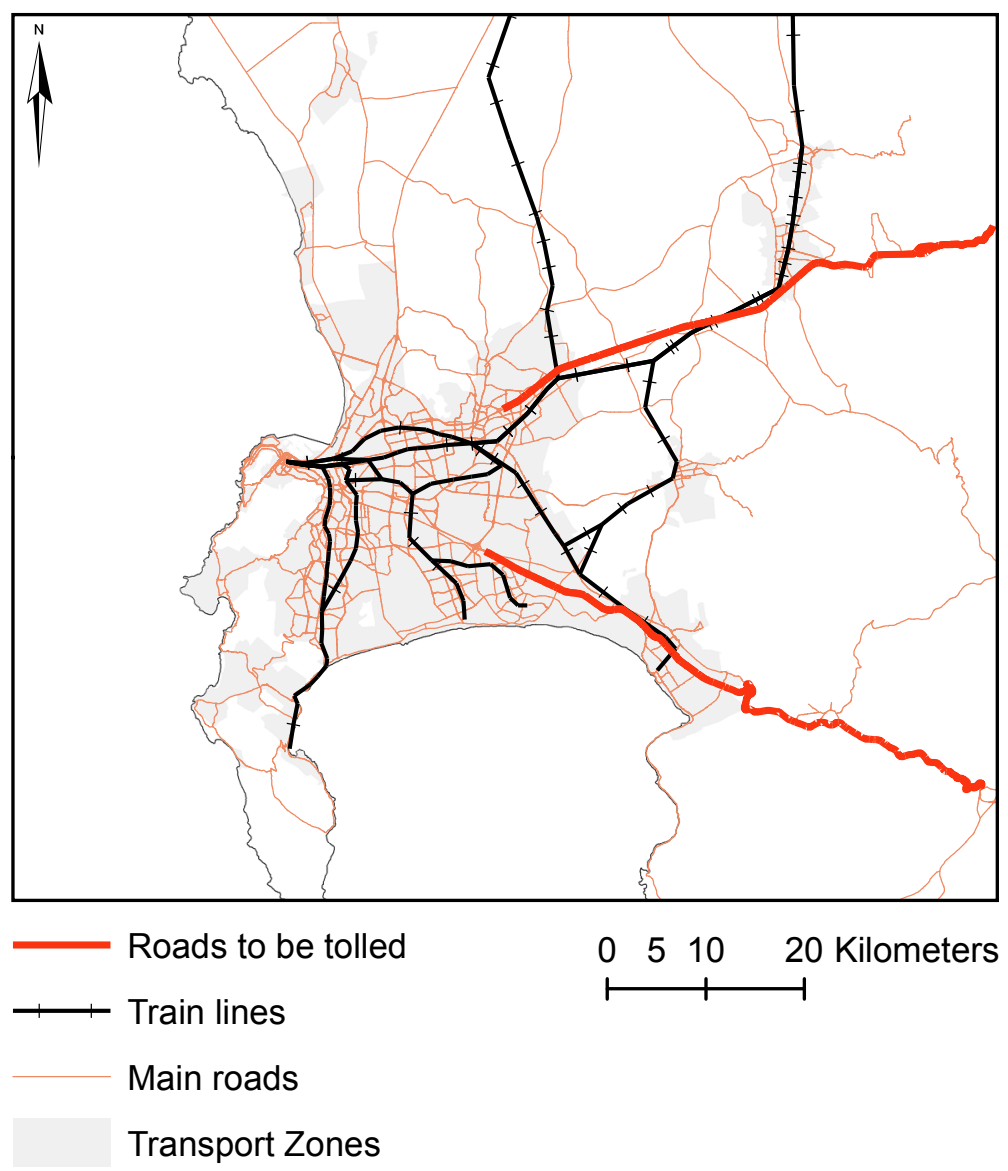

Figure1: Main roads (2010) and train lines (2013) of the Cape Town metropolitan region Source: City of Cape Town (2010)

'SANRAL has been given the mandate by the South African government to implement tolls on the roads under its jurisdiction (Government Gazette 1998). 
Not only has attention to the possible distributional effects of a toll in the challenging context of a developing country been absent, but also little attention has been paid to the consequences of road pricing within a spatial context. There has been particularly little discussion on the implications of roadpricing policies on the accessibility of activity locations (Tillema 2007; Tillema et al. 2008; CondeçoMelhorado, Gutiérrez, and García-Palomares 2011; Neutens, Schwanen, and Witlox 2011; Tillema et al. 2011). Tillema (2007, 31-32) advances: "The introduction of road-pricing measures affects the transport costs of a road network (...) and hence has an immediate impact on the transport system. Changes in the transport system in turn affect the accessibility of activity locations." This raises questions with regard to the equity effects of a toll on the accessibility of activity locations in the Cape Town metropolitan region.

It follows that the aim of this study is to provide an ex ante insight into the equity effects of a toll charge on traffic diversion and the geographical accessibility of work locations in the Cape Town metropolitan region. The methodology is based on a static traffic assignment model and aggregate accessibility measures, computed using two GIS-software packages: ArcGIS and Flowmap. To account for its objective, the remainder of this paper is organized as follows. Section 2 advances a conceptual framework to assess the equity effects in terms of accessibility. Section 3 deals with the adopted methodology. Section 4 reports on the expected traffic diversion effects and the expected outcomes of the accessibility measures employed. Finally, section 5 discusses the results and tries to assess the equity of a toll in the Cape Town metropolitan region.

\section{$2 \quad$ Literature review}

Whereas the academic literature with respect to road pricing dates back to Pigou (1920) and Vickrey (1969), the concept has regained academic and public interest as a result of growing transport and road funding problems around the world (Mayeres 2000; Glaister and Graham 2006; Litman 2011; Rouwendal and Verhoef 2006; Anas and Lindsey 2011; Ben-Elia and Ettema 2011; Inturri and Ignaccolo 2011). However, scholars have not yet reached consensus with regard to the question whether the burdens and benefits of road pricing are equally distributed along economic and spatial lines (Teubel 2000; Bonsall and Kelly 2005; Bureau and Glachant 2008; Levinson 2010)

With regard to these distributional effects, Taylor and Norton (2009, 31), for instance, assert that some scholars fear "that poor people will simply be priced off roads and transit vehicles, leaving freeflowing systems for the wealthy." By the same token, Levinson (2010, 44) argues that road-pricing policies are more detrimental to low-income groups and posits that "pricing properly implemented improves efficiency, but may harm equity (...) in a way that revenue recycling is required to remedy." Eliasson and Mattsson (2006) conducted a case study in the Stockholm region and in turn argue that distributional effects will mainly depend on initial travel behavior and revenue distribution. The study asserts that particularly high-income residents pay most charges given their higher trip frequencies. Rich and Nielsen (2007), on the other hand, suggest that distributive outcomes are contingent on contextual factors such as the quality of public transport system and the urban structure.

In post-apartheid Cape Town, where many people rely on road transport, especially the contextual factors seem to be important. The racial segregation policies of apartheid have confronted the contemporary society with a spatial mismatch between work and home locations (Naudé 2008). The combination of fast-paced spatial developments with a lack of land-use-based transport planning and low levels of investment in the rail system, left formal public transport in an unfavorable position; this largely contributed to the dominant position of the informal economy in the realm of transport provision. Walters (2008, 102) maintains: "The current rail commuter network (...) is a reflection of the political past of South Africa whereby labor was conveyed between distant dormitory townships on the outskirts of the 
cities and jobs in and around the cities." In particular the poor, predominantly black people living in the townships on the periphery are unable to reach the low-skilled jobs in the central areas by means of formal public transport and are thus captive to road transport such as the minibus taxi (Walters 2008).

The spatial inequalities inflicted by the apartheid regime, the lack of an adequate formal public transport system, and a high overall dependency on road transport, yields the hypothesis that a toll in this region will take a proportionally greater amount from those on lower incomes. As Standish (2008, 106) argues: "It can be expected that the increased cost of a regular taxi or bus commute [as a consequence of a toll] would be felt by poorer people." Additionally, as Bonsall and Kelly (2005) argue, the introduction of a toll will mainly benefit the more affluent private car-owners. In combination with the declaration by the Department of Transport (1996) that states that people should not spend more than 10 percent of their disposable income on transport, this raises the question of which areas and which population groups are most likely to be affected. Langhmyhr (1997) proposed, with regard to this question, a basic conceptualization of winners and losers of implementing a toll charge on an existing road network, as shown in Table 1.

Table 1: Possible impacts of implementing a toll charge on an existing road network on travel behavior

\begin{tabular}{|c|c|c|}
\hline Travel behavior & Winners & Losers \\
\hline Unchanged (fee charged) & $\begin{array}{l}\text { Travelers valuing the time savings over } \\
\text { fee } \\
\text { High-income commuters }\end{array}$ & $\begin{array}{l}\text { Travelers valuing the time savings below } \\
\text { the fee, but having only unattractive travel } \\
\text { alternatives } \\
\text { Lower-and upper-middle income commuters } \\
\text { (car captive) }\end{array}$ \\
\hline $\begin{array}{l}\text { Changed to toll facility (tolled } \\
\text { on) }\end{array}$ & $\begin{array}{l}\text { Persons now finding it profitable to un- } \\
\text { dertake a trip, even with a fee, because } \\
\text { of a reduction in travel time } \\
\text { High-income people (voluntary trips) }\end{array}$ & \\
\hline $\begin{array}{l}\text { Changed from toll facility } \\
\text { (tolled off) }\end{array}$ & $\begin{array}{l}\text { Travelers who switch from driving to } \\
\text { public transport (e.g., bus), which is } \\
\text { now better because of lower congestion } \\
\text { Lower middle-income commuters }\end{array}$ & $\begin{array}{l}\text { Person abstaining from travel or accepting } \\
\text { less attractive travel times, routes, or modes } \\
\text { to avoid fee } \\
\text { Lower middle-income commuters (car captive) }\end{array}$ \\
\hline $\begin{array}{l}\text { Unchanged (fee not charged } \\
\text { tolled) }\end{array}$ & $\begin{array}{l}\text { Public transport users experiencing time } \\
\text { savings } \\
\text { Captive public transport commuters in } \\
\text { case of a revenue distribution }\end{array}$ & $\begin{array}{l}\text { Persons experiencing congestion on road } \\
\text { or on public transport caused by persons } \\
\text { who have changed travel behavior to avoid } \\
\text { the toll } \\
\text { Low-income commuters (public transport } \\
\text { captive) }\end{array}$ \\
\hline
\end{tabular}

Source: Langmyhr $(1997,28)$; extended by Levinson $(2010,47)$

With respect to the losers, Langmyhr (1997) suggests a tripartite classification: (1) commuters willing to avoid the charge but having no attractive alternatives to do so; (2) commuters priced off the roads or switching to different routes or off-peak travel times because they cannot afford the charge; and (3) commuters experiencing congestion as a consequence of people changing their routes or changing their modes in order to avoid the toll. This suggests that the people considered to be losers all experience additional constraints in reaching their planned destination; commuters who use the road on a daily basis in particular. Accordingly, these commuters might try to find alternatives to compensate for these additional constraints by means of shifting toward a different transport mode, switching to off-peak travel

${ }^{2}$ Although government officials declared that qualifying minibus taxis will be exempt from paying the toll, this is not formalized yet (Standish 2008; Government Gazette 2012b). This paper, therefore, takes a "what if" approach regarding this statement. 
times, using a different route or by abstaining from the trip. In the long term, people may even decide to change their residential location (Tillema 2007).

In the South African context, however, as a result of the distorted spatial organization caused by the apartheid planning policies, changing residential location for people on a low income is only a theoretical possibility. In addition, formal public transport is heavily underdeveloped and the distances are too large to make non-motorized transport a viable option (The World Bank 2002; Lucas 2011). The same applies to peak-hour avoidance; people on a low salary often have inferior possibilities to arrange for flexible work hours (Eliasson and Lundberg 2002). Because the toll in the region will not be part of a package solution to improve urban transportation, this implies that the people who are not able to pay the toll de facto have only two options to compensate for the additional costs: changing route, or accepting a decline in terms of their economic access into the transport system (Dimitriou 2006). Both options, however, may negatively affect the foremost product of the transport system: accessibility.

Accessibility, as conceptualized by Geurs and Van Wee (2004), is constituted by four interrelated components: a land-use component, a transportation component, a temporal component, and an individual component. This suggests that a change in one of these components will impact on the accessibility to activity locations. This implies that when "the disutility for an individual to cover the distance between an origin and a destination using a specific transport mode (Geurs and van Wee 2004, 129)" increases, the accessibility to activity locations will decrease. Along these lines, it can be argued that a toll can impact on this disutility, both directly through the fee and indirectly through diversion from the tolled road. Accordingly, a conceptual framework has to be drawn with which it can be assessed whether the spatial implications are spatially and socio-economically unequal. In the following, a measure of equity will be advocated, which translates the concept of accessibility into the measurement of opportunities.

The introduction of the notion of opportunities in the realm of determining the equity effects of a toll road might be unique, but it is derived from a more philosophical debate with respect to the concept of distributive justice: the egalitarian "Theory of Justice" as advanced by political philosopher John Rawls (1971) in particular (Smith 1994; Christman 2002; Taylor and Norton 2009). Rawls (1971) advocates the view that a true equal society can only be achieved when everybody has the same chance to become affluent or impoverished - when everybody has the same opportunities. This idea is articulated by the difference principle, which conveys the idea that: "Social and economic inequalities are to be arranged so that: (a) they are attached to positions that are open to everyone under conditions of fair equality of opportunity; (b) they are arranged to the greatest benefit to the least advantaged members of society (Elvik 2009, 820)." Consequently, equity in this conceptualization presupposes equity in opportunities.

This equity of opportunity in turn can be conceived as a yardstick for assessing social policy: To what extent does a policy disproportionately affect the opportunities of one group over another group? Furthermore, it is the equality of opportunity that makes the Theory of Justice particularly suitable for incorporating a spatial perspective. A transport system yields accessibility and therefore provides people, commuters, for example, with the opportunity to reach activity locations on geographically dispersed locations. Given these characteristics, accessibility is particularly suitable for ex ante policy evaluations in which questions of equity and justice play a role (van Wee and Lucas 2012). The accessibility of activity locations therefore functions as both a heuristic and a conceptualization of equity to assess to what extent a toll in the Cape Town metropolitan region affects the road toward spatial equity.

A lack of viable alternatives to compensate for the additional costs of a toll, especially for people on a low income, may damage their economic access into the transport system (Dimitriou 2006) and may thus have a regressive effect on the geographical accessibility to urban opportunities such as work locations. It should be noted that were the toll to be part of an integrated land-use and transport plan 
in which, for instance, revenues were used to invest in a more efficient and affordable public transport system, a toll charge could actually help to address inequalities in the current transport system. Earmarking the toll revenues for transportation in ways that would benefit the transport-disadvantaged lower income people, for instance, could actually have progressive effects (Ecola and Light 2010).

As SANRAL is planning to impose the toll in the region characterized by unequal spatial, economic and social opportunities, it is hypothesized that the burdens and benefits of a toll will not be equally distributed along economic and spatial lines. Given the inherent relations between income and space in post-apartheid Cape Town, it is also expected that the distributional effects along economic lines will be spatially expressed. If this hypothesis holds, this will put a constraint on the institutionalization of spatial justice - a form of justice that recognizes the distributional spatial element of citizens' rights and responsibilities (Cresswell 2006).

\section{Data and methods}

To assess the changes in geographical accessibility of activity locations as a result of a toll, comparisons were made between the accessibility of work locations in a reference scenario in which no toll is being charged and the accessibility of work locations in two scenarios in which a toll is being charged on parts of the N1 and N2. Although the operationalization of accessibility is discussed later, the accessibility effects of a toll were essentially estimated as follows:

$\Delta \mathrm{A}_{\mathrm{i}}=\mathrm{A}_{\mathrm{iSn}}-\mathrm{A}_{\mathrm{iS} 0}$

$\Delta \mathrm{A}_{\mathrm{i}}$ represents the change in accessibility of zone $\mathrm{i}, \mathrm{A}_{\mathrm{iSn}}$ is the accessibility in a toll scenario and $\mathrm{A}_{\mathrm{iSO} 0}$ stands for the accessibility in the reference scenario. Table 2 gives an overview of these scenarios.

Table 2: Toll scenarios; charges adapted from the current toll charges in Gauteng, South Africa

\begin{tabular}{|l|c|c|}
\hline \multicolumn{1}{|c|}{ Charged roads } & Scenario & Charge (per kilometer) \\
\hline No charge & S0 & R 0.00 \\
\hline Low estimate (e-tag tariff) & S1 & R 0.30 \\
\hline High estimate (base tariff) & S2 & R 0.58 \\
\hline
\end{tabular}

Source: Government Gazette (2012a); Exchange rate: $€ 1.00$ equals approximately R14.00

Because the computation of geographical accessibility measures requires a locational component as unit of analysis, 836 transport zones were extracted from the transport model of the municipality of Cape Town (City of Cape Town 2010). Figure 2 shows these zones; natural barriers have been added to illustrate the spatial confinement of the region. The attributes of the zones included trip generations and attractions that were derived from modeled origin-destination matrices (2010), for daily car and public transport commuters only. In total this yielded over 900,000 commuters, a number that is in line with the 2001 national census results (City of Cape Town 2010). Because only information on commuters was available, the dataset did not allow for an analysis of activity locations other than work locations. Although questions might be posed with regard to the quality and the detail of the data, it should be emphasized that this is the only existing dataset for this region. 


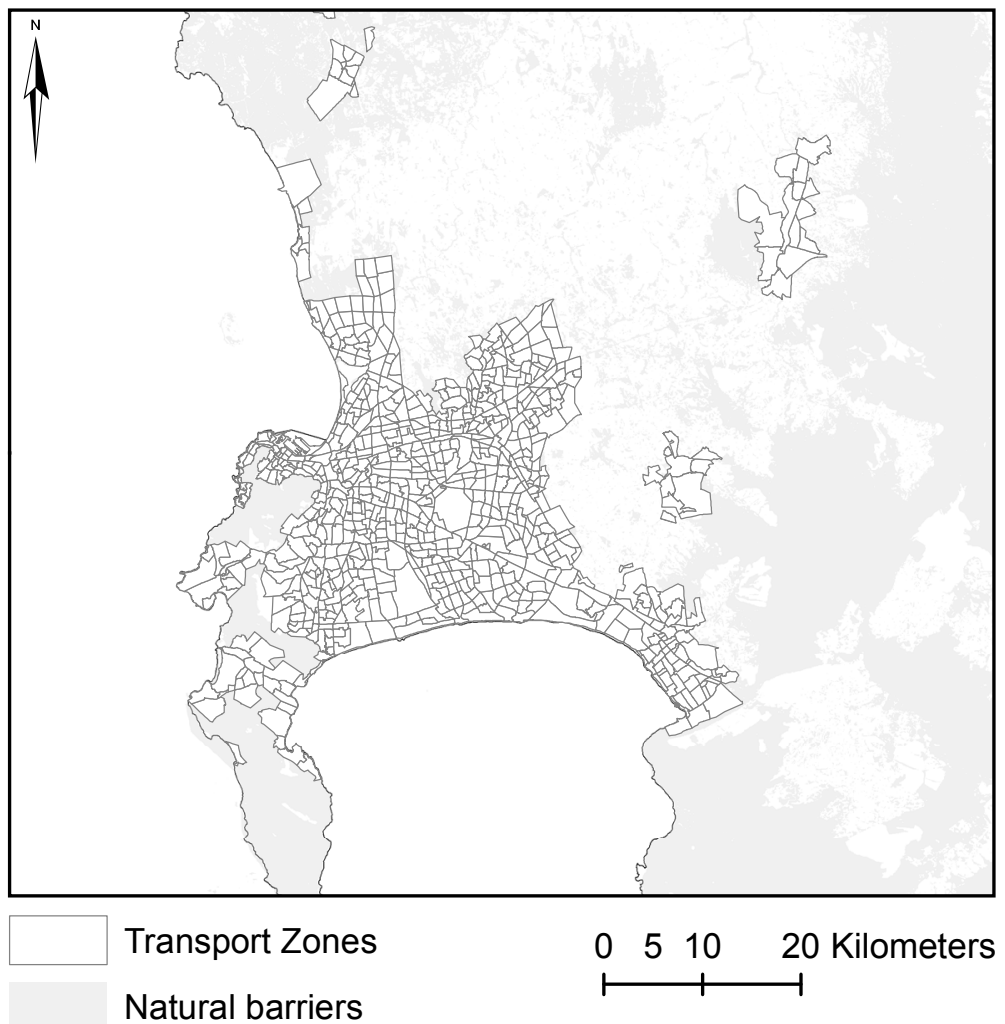

Figure 2: Transport zones of the Cape Town metropolitan region (2007)

Source: City of Cape Town (2010)

Apart from a locational component, the measurement of geographical accessibility required a digital transport network with impedance values between all origins $i$ and destinations $j$. This network contained the major roads as well as the local streets of the complete Cape Town metropolitan region, permitting the analysis of the spatial variability of a toll. Each arc in the network contained information on the average network speed, which combined with the length was used to calculate the link travel times that served as input for the calculation of the impedance values. Train lines were added manually and connected to the road network, allowing for a multi-modal public transport analysis incorporating trains and minibus taxis; an overview of the major roads and train lines was already given in Figure 1.

As a measure of impedance between the places of origin and destination, a generalized transport cost function was used. The generalized costs (GC) for any road segment $\mathrm{n}$ consisted of a monetary value assigned to travel time (VOT) multiplied by the link travel time (TT) of $\mathrm{n}$ and the vehicle operating cost (VOC) associated with traversing $n$. The use of monetary values facilitated the incorporation of the toll fees $(\mathrm{T})$ :

$\mathrm{GCn}=\left[\left(\mathrm{VOT}^{*} \mathrm{TT}_{\mathrm{n}}\right)+\mathrm{VOC}_{\mathrm{n}}\right]$

$\mathrm{GCn}=\left[\left(\operatorname{VOT}^{*} \mathrm{TT}_{\mathrm{n}}\right)+\mathrm{VOC}_{\mathrm{n}}\right]+\mathrm{T}_{\mathrm{n}}$ 
The generalized costs (GC) for any public transport segment $\mathrm{n}$ were calculated in the same fashion, except that the vehicle operating cost was replaced by a fare $(\mathrm{F})$ :

$\mathrm{GCn}=\left[\left(\mathrm{VOT}^{*} \mathrm{TT}_{\mathrm{n}}\right)+\mathrm{F}_{\mathrm{n}}\right]$

Furthermore, to account for benefits of the toll, the average speeds of the tolled roads in the toll scenarios were increased to the maximum speeds and the VOC was slightly decreased. To address the delay caused by the toll plazas, time penalties of one minute were given to all highway entrances at issue (Standish 2008). Table 3 and Table 4 show the values employed for the segments of the road network and the public transport network, respectively. Because the dataset did not contain information on the distribution of income groups per transport zone, the VOT employed for transport zone i was based on the income category of that transport zone as a whole.

Table 3: Parameters generalized cost function: VOT per hour and VOC per kilometer

\begin{tabular}{|l|c|c|c|}
\hline Income Category & Income per annum & VOT per hour & VOC per kilometer \\
\cline { 1 - 3 } Low & $<\mathrm{R} 15,855$ & $\mathrm{R} 8.06$ & \multirow{2}{*}{ R 2.90 (No toll road) } \\
Middle & $\mathrm{R} 15,855-$ & $\mathrm{R} 24.74$ & $\mathrm{R} 2.64$ (Toll road) \\
\cline { 1 - 2 } High & $>\mathrm{R} 78,487$ & $\mathrm{R} 77.20$ & \\
\hline
\end{tabular}

Source: City of Cape Town (2010); Exchange rate: $€ 1.00$ equals approximately R14.00

Table 4: Parameters generalized cost function: public transport speeds and fares per kilometer

\begin{tabular}{|l|c|c|}
\hline Public Transport Mode & Average speed & Average fare per kilometer \\
\hline Minibus Taxi & $\begin{array}{c}\text { Average speed road } \\
\text { segment }\end{array}$ & R 1.50 \\
\hline Train & 50 kilometers/hour & R 0.50 \\
\hline
\end{tabular}

Estimations based on Letebele, Masemola, and Mokonyama (2009) and Metrorail (2012)

With the generalized cost function as input, the accessibility of work locations could be assessed by means of two accessibility measures appropriate for assessing aggregate accessibility (de Jong and van Eck 1996); the first one being a potential measure. This measure, one of the most widely used measures in the literature (Condeço-Melhorado, Gutiérrez, and García-Palomares 2011) in which smaller and/ or more distant opportunities provide diminishing influences (Tillema 2007, 34).” It is commonly formulated as:

$$
P_{i}=\sum_{n}^{j}=1 \frac{M_{j}}{c_{i j}^{\beta}}
$$

where $P_{i}$ is the potential accessibility of zone $i, M_{j}$ is the attraction of the destination $j$, and $C_{i j}$ represents the summed generalized costs over the network between $i$ and j. Lastly, parameter $\beta$ represents the distance decay factor. An exponential function was employed for $\beta$, because this is most closely related to travel behavior (Geurs and van Wee 2004).

A drawback of the potential measure, however, is that it tends to overstress the importance of short distances. Accordingly, a second measure was used: the proximity count. This measure counts for each zone the number of work locations within a fixed impedance (Geurs and Ritsema van Eck 2001). Because choosing this fixed impedance is slightly arbitrary, the current average trip distance over the 
network was used. These average trip distances were calculated using the modeled origin-destination matrix, the generalized cost functions, and the income category of the transport zone (Table 5). Since no recent data were available on the percentage of low-, middle-, and high-income travelers per transport zone, the income category of each zone was derived from the average income per annum. These average incomes, in turn, were estimated by the City of Cape Town (2010) by looking at the average property prices in the area.

Table 5: Income category per transport zone and estimated average monetary commuter distances

\begin{tabular}{|l|c|c|c|}
\hline \multicolumn{1}{|c|}{$\begin{array}{c}\text { Income category transport } \\
\text { zone }\end{array}$} & $\begin{array}{c}\text { Average income per } \\
\text { annum }\end{array}$ & $\begin{array}{c}\text { Average trip distance } \\
\text { by car }\end{array}$ & $\begin{array}{c}\text { Average trip distance } \\
\text { by public transport }\end{array}$ \\
\hline Low-income & $<\mathrm{R} 25,000$ & $\mathrm{R} 38.42$ & $\mathrm{R} 15.53$ \\
\hline Lower middle-income & $\mathrm{R} 25,000-\mathrm{R} 100,000$ & $\mathrm{R} 41.37$ & $\mathrm{R} 17.43$ \\
\hline Upper middle-income & $\mathrm{R} 100,000-\mathrm{R} 250,000$ & $\mathrm{R} 47.78$ & $\mathrm{R} 18.92$ \\
\hline High-income & $>\mathrm{R} 250,000$ & $\mathrm{R} 63.75$ & $\mathrm{R} 39.25$ \\
\hline
\end{tabular}

Source: City of Cape Town (2010)

The generalized cost functions, with various parameters for the different toll scenarios, also enabled the calculation of least-cost paths between the centers of all transport zones. In combination with the modeled trip origins and destinations, the most likely distribution of traffic over the road network was simulated using a shortest path algorithm. This exercise was conducted for all of the three scenarios by means of a static traffic assignment model. As a direct result of the available data, the model only took route choice into account. These data did not allow for a more advanced model incorporating mode choice and trip frequency. The differences in traffic assignment between the reference scenario and the two toll scenarios were assessed in the same fashion as the changes in accessibility were calculated. The GIS-extension Flowmap, specifically designed for handling spatial interaction data and accessibility analyses, was employed for calculating the accessibility measures and carrying out the traffic assignments, whereas ArcGIS was used for its general analysis and map-making capabilities.

\section{Accessibility effects of a toll in the Cape Town metropolitan region}

This penultimate section presents the results of the analyses with regard to the impact of a toll on traffic diversion and the geographical accessibility of work locations in the Cape Town metropolitan region. First, the impact of a toll on traffic distribution is evaluated. Second, the outcomes of the potential measures and the proximity counts are discussed.

Traffic flows have been assigned to the digital transport network in the reference scenario (S0) and in the two toll scenarios ( $\mathrm{S} 1$ and S2). Because the origin-destination relationships did not include data on the share of income groups per zone, the traffic assignment was executed for every VOT using all commuters within the dataset. Table 6 shows for the three scenarios the sum of all flows assigned to the segments of the N1 and N2 national highways that will be subject to a toll. Interestingly, the traffic attraction of both highway segments had the highest value when a high VOT was used. This may be explained by looking at the total generalized costs. With a higher value of time (VOT), the vehicle operating cost (VOC) accounts for a smaller proportion of the total generalized costs. This implies that time becomes relatively more important than the actual distance traveled.

Turning now to the differences in traffic attraction for the different scenarios, the largest decrease is found in the high toll scenarios, particularly for commuters with a low or middle VOT. Table 6 shows that the busy N1 highway has a traffic attraction of 222,910 commuters for a low VOT in S0; a number 
Table 6: Traffic attraction car network for the toll parts of the N1 and N2 in different VOT situations and toll scenarios, Cape Town metropolitan region (2010) *

\begin{tabular}{|l|c|c|c|c|c|c|}
\hline \multicolumn{1}{|c|}{ VOT } & S0 N1 & S1 N1 & S2 N1 & S0 N2 & S1 N2 & S2 N2 \\
\hline Low & 222,910 & 220,443 & 37,769 & 90,058 & 85,609 & 19,632 \\
\hline Middle & 234,176 & 230,499 & 146,397 & 101,934 & 92,664 & 37,503 \\
\hline High & 261,242 & 254,875 & 233,383 & 129,038 & 117,655 & 108,165 \\
\hline
\end{tabular}

* The traffic attraction equals the sum of all flows assigned to all individuals road segments at issue and therefore does not represent the actual number of commuters. The nature of the data did not allow for a more accurate measure.

that decreases by more than 80 percent to 37,769 in S2. Although the N2 attracts less traffic than the $\mathrm{N} 1$, a decline in traffic attraction can also be observed here. Whereas the traffic attraction consisted of 101,934 commuters in S0 for a middle VOT, it decreased by 63 percent to 37,503 commuters in S2. However, for both the N1 and N2 it is shown that the diversion effects in a low toll scenario are marginal. This suggests that in $S 1$ the time gains as a consequence of higher travel speeds on the toll roads to a large extent weigh up against the additional costs of the toll.

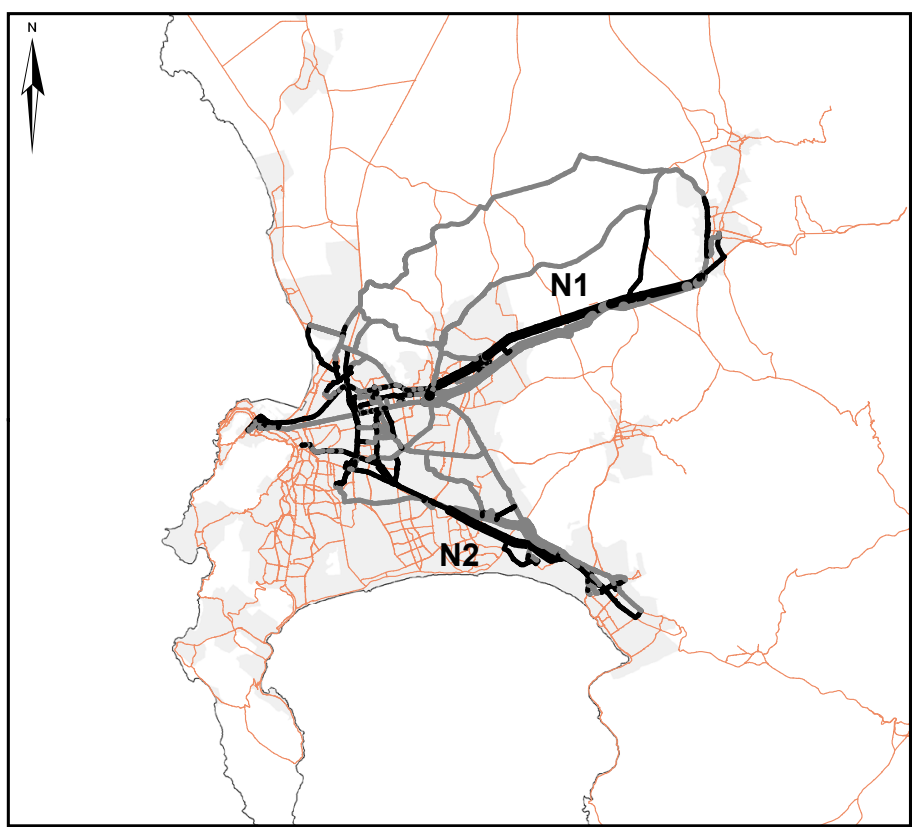

\section{Decrease in flows}

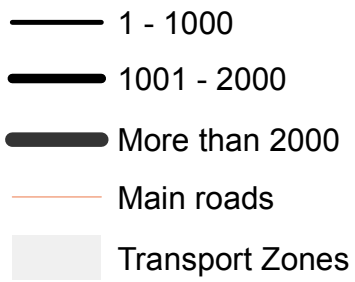

Increase in flows

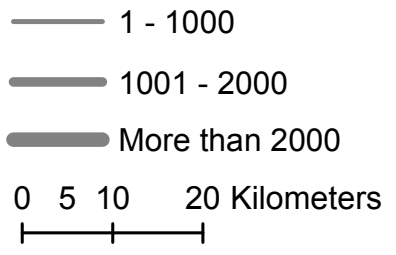

Figure 3: Changes in traffic attraction for a middle VOT in a high toll scenario, Cape Town metropolitan region (2010) Source: City of Cape Town (2010)

\footnotetext{
${ }^{3}$ As noted earlier, government officials have declared that qualifying minibus taxis will be exempt from paying the toll, but this is not formalized yet (Standish 2008; Government Gazette 2012b). This paper therefore takes a what if approach regarding this statement.
} 
What is striking is that for commuters with a high VOT a decrease in traffic attraction can be noticed as well but the decrease is less dramatic. For instance, the N1 attracts 261,242 commuters in S0, but this number only decreases to 254,875 and 233,383 in S1 and S2, respectively. This suggests that commuters with a high VOT are more likely to pay the toll because these costs only constitute a small proportion of their total generalized costs. For low-income commuters, on the other hand, the toll amounts to a larger share of their total generalized costs, and thus their likelihood to take an alternative route increases. By way of illustration, Figure 3 shows the changes in traffic attraction for commuters with a middle VOT in a high toll situation. The figure shows that alternative routes throughout the region become more attractive than the more expensive toll roads.

If we now turn to the traffic attraction for the toll parts of the N1 and N2 for the public transport network, the outcomes seem to be consistent with the results for the car network ${ }^{3}$, as shown in Table 7. The increasing number of attracted commuters concurrent with an increase in the VOT is likely to be explained by the diminishing share of the fares in the total generalized costs; this is particularly visible in the numbers for the N2. Because the fares are based on the physical distance traveled, it is likely that commuters with a low and middle VOT prefer shorter routes in terms of distance, whereas commuters with a high VOT opt for shorter routes in terms of travel time.

Table 7: Traffic attraction public transport network for the toll parts of the N1 and N2 in different VOT situations and toll scenarios, Cape Town Metropolitan region (2010)*

\begin{tabular}{|l|c|c|c|c|c|c|}
\hline \multicolumn{1}{|c|}{ VOT } & S0 N1 & S1 N1 & S2 N1 & S0 N2 & S1 N2 & S2 N2 \\
\hline Low & 31,094 & 30,876 & 1,127 & 6,997 & 6,314 & 6,195 \\
\hline Middle & 65,749 & 61,787 & 58,715 & 7,069 & 6,491 & 6,491 \\
\hline High & 129,853 & 120,755 & 119,589 & 53,026 & 49,448 & 47,349 \\
\hline
\end{tabular}

* The traffic attraction equals the sum of all flows assigned to all individual road segments and therefore does not represent the actual number of commuters. The nature of the data did not allow for a more accurate measure.

When turning to the attraction values in the different toll scenarios, the limited impact of the toll becomes apparent. Only commuters with a low VOT traveling over the N1 in a high toll situation seem to divert to alternative routes. A part of this result, however, may be explained by the limitations of the dataset. The dataset suggested only few public transport commuter trips in the low-income transport zones surrounding the $\mathrm{N} 2$, which might be an underestimation. On the other hand, given the high rates of unemployment in this area, it also could be the case that there are simply not enough people who have to commute on a daily basis to their jobs. Notwithstanding these remarks, the results do suggest that if minibus taxis would not be exempt from the toll, traffic diversions are likely to occur. This suggestion is supported by the fact that predominantly low-income commuters travel by minibus taxis (Walters 2008; Lucas 2011).

So far, thus, the outcomes indicate that particularly low-income commuters will divert to alternative routes. This raises the question as to what extent these inequalities translate into inequalities in terms of geographical accessibility. The average potential score was employed as first measure to assess the geographical accessibility in the region. The potential scores were calculated for both the car network and the public transport network for each transport zone individually and scaled to the highest overall value. Table 8 summarizes the mean scores for the car network.

The results indicate that some within group variation is present with scores varying between 9.57 and 17.14 (S0), whereas the between group variation is minimal. Particularly the transport zones classified as upper middle-income have a relatively good accessibility; a possible explanation for this is that on average the middle-income transport zones are situated relatively close to the employment centers. 
Table 8: Accessibility by car. Crosstab average potential scores with regard to work locations, Cape Town Metropolitan Region (2010)

\begin{tabular}{|l|l|c|c|c|}
\hline $\begin{array}{c}\text { Income Category } \\
\text { Transport Zone }\end{array}$ & \multicolumn{1}{|c|}{ VOT } & S0 & S1 & S2 \\
\hline Low-income & Low & 9.57 & 9.56 & 9.55 \\
Lower middle- & Middle & $(7.06)$ & $(7.06)$ & $(7.07)$ \\
income & \multirow{2}{*}{ Middle } & $(10.00)$ & 13.29 & 13.28 \\
Upper middle- & 17.14 & $(10.00)$ & $(10.00)$ \\
income & \multirow{2}{*}{ High } & $(11.15)$ & 17.14 & 17.12 \\
High-income & 13.28 & $11.15)$ & $(11.16)$ \\
\hline
\end{tabular}

Standard deviation in between brackets

This cannot be said of the low-income transport zones. These zones have overall the lowest scores. Contrary to the hypothesis, however, none of the categories of transport zones witness a significant decrease in accessibility. This suggests that neither the additional costs of a toll nor the incremental costs caused by switching to an alternative route have on average a large impact on the geographical accessibility of work locations.

Turning now to the average potential scores by public transport, the same pattern emerges, as shown in Table 9. The within group variation is again significant with scores varying between 55.22 and $80.78(\mathrm{~S} 0)$, whereas the between group variation is minimal. A notable difference, however, is that the potential scores are much higher compared to the scores by car. This suggests that due to the lower monetary costs of the (informal) public transport system, accessibility as a whole increases.

Table 9: Accessibility by public transport. Crosstab average potential scores with regard to work locations, Cape Town Metropolitan Region (2010)

\begin{tabular}{|l|l|c|c|c|}
\hline $\begin{array}{c}\text { Income Category Transport } \\
\text { Zone }\end{array}$ & \multicolumn{1}{|c|}{ VOT } & So & S1 & S2 \\
\hline Low-income & Low & $\begin{array}{c}55.22 \\
(15.48)\end{array}$ & $\begin{array}{c}55.14 \\
(15.53)\end{array}$ & $\begin{array}{c}55.11 \\
(15.56)\end{array}$ \\
\hline \multirow{2}{*}{ Lower middle-income } & \multirow{2}{*}{ Middle } & 58.01 & 57.89 & 57.86 \\
& & $(16.86)$ & $(16.96)$ & $(17.01)$ \\
\hline \multirow{2}{*}{ Upper middle-income } & \multirow{2}{*}{ Middle } & 61.81 & 61.70 & 61.66 \\
& & $(17.17)$ & $(17.10)$ & $(17.38)$ \\
\hline \multirow{2}{*}{ High-income } & \multirow{2}{*}{ High } & 80.78 & 80.57 & 80.53 \\
& & $(12.75)$ & $(12.91)$ & $(12.97)$ \\
\hline
\end{tabular}

Standard deviation in between brackets

What is interesting is that in the car network the upper middle-income transport zones had on average the highest scores, whereas now the high-income transport zones have the highest scores. This inconsistency may be due to the calibration of the distance decay parameters associated with the different generalized costs functions. The calibration of these parameters was based on the modeled origin-destination matrix for every VOT situation, and due to the limited number of public transport commuters stemming from high-income transport zones, the distance decay parameter may have been underestimated. Another explanation could be that the low-income transport zones are better connected to the formal public transport system (Walters 
2008). However, none of categories of transport zones witnesses on average a disproportional decrease in their accessibility.

Turning now to the outcomes of the proximity counts, Table 10 indicates that in the base scenario high-income commuters can reach significantly more jobs than low-income commuters can. These differences may be explained by the different fixed impedances employed: Commuters departing from a high-income zone have a higher impedance value (Table 5) and thus can cover a larger distance and therefore reach more work locations despite the higher costs associated with their travel. Also the geographical distribution of origins and destinations seems to be important again: The upper middleincome transport zones can reach the highest number of jobs within their fixed impedance. A possible explanation for this is that both for lower middle-income and upper middle-income transport zones, the same VOT was employed, whereas the fixed impedance of the latter was set to be higher. Given the outcomes of the potential measure, however, it is likely that this outcome can be mainly ascribed to the location of the upper middle-income transport zones. This is supported by the large standard deviation, which hints toward the presence of spatial variability within the categories of transport zones.

What is striking when looking at the toll scenarios is that the expected decrease in the number of accessible work locations is almost absent. High-income transport zones witness on average a small decline of 339 ( 0.14 percent) for S1 and 541 (0.22 percent) opportunities for S2. Low-income transport zones, witness an even smaller decline of 51 (0.04 percent) for S1 and 111 (0.09 percent) for S2. In fact, a supplementary examination of the largest decrease for S2 showed that the worst case for the low-income transport zones was 2407 (8.03 percent) and for the high-income transport zones 32,014 (26.99 percent). It may therefore be that the impact of a toll is mainly located close or alongside the toll roads. Figure 4, which shows the average decrease in accessibility for each transport zone in S2, supports this notion.

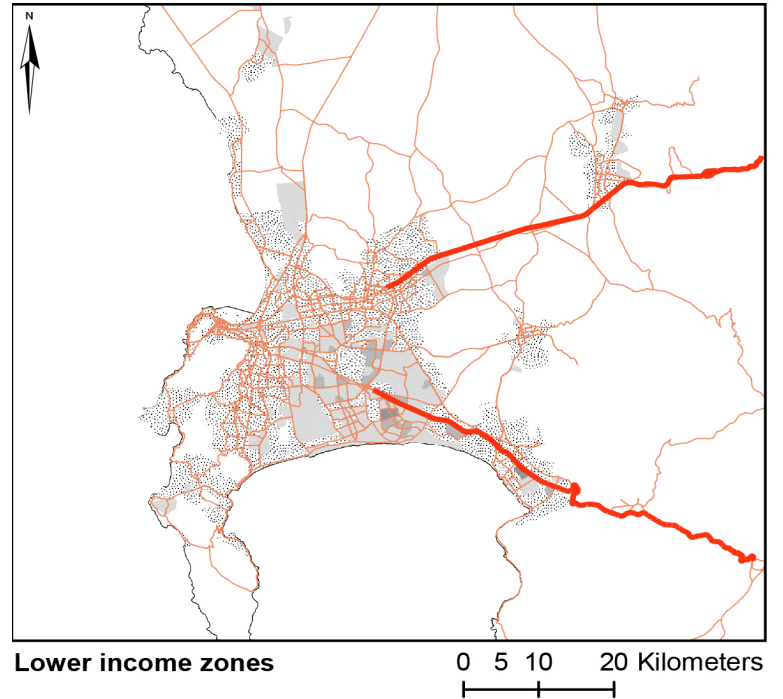

No decrease

$0.01 \%-4.99 \%$

$5.00 \%-9.99 \%$

$10.00 \%-14.99 \%$

$15.00 \%-19.99 \%$

Over $20.00 \%$

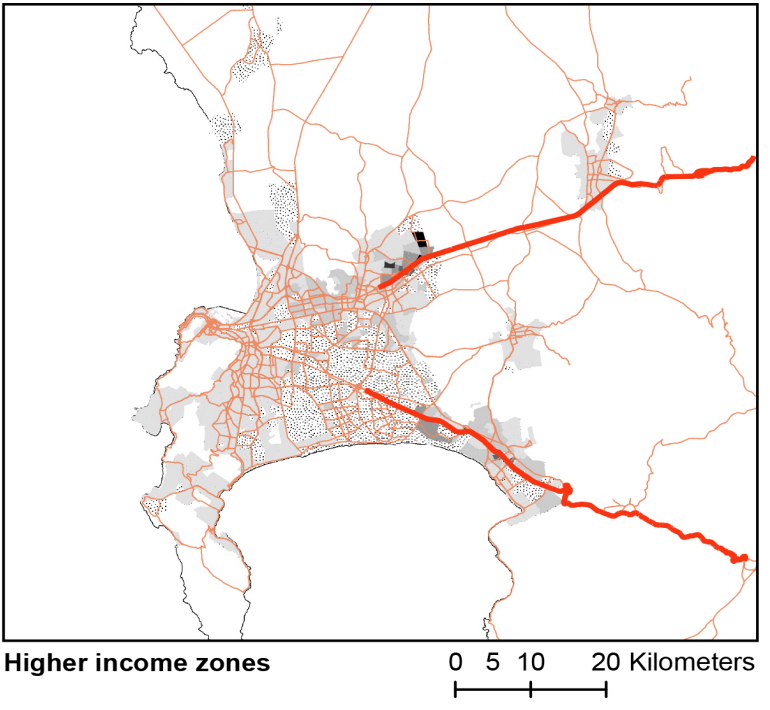

No decrease

$0.01 \%-4.99 \%$

$5.00 \%-9.99 \%$

$10.00 \%-14.99 \%$

$15.00 \%-19.99 \%$

Over $20.00 \%$

Figure 4: Percentage decrease in proximity count per transport zone in a high toll scenario, Cape Town metropolitan region (2010)

Source: City of Cape Town (2010) 
Table 10: Accessibility by car. Crosstab average proximity count with regard to work locations within fixed impedance, Cape Town Metropolitan region (2010)

\begin{tabular}{|c|c|c|c|c|c|c|}
\hline $\begin{array}{c}\text { Income Category } \\
\text { Transport Zone }\end{array}$ & VOT & Impedance & Statistics & So & S1 & S2 \\
\hline \multirow{5}{*}{ Low-income } & \multirow{5}{*}{ Low } & \multirow{5}{*}{ R 38.42} & Mean (Std. Deviation) & $124,579(143,721)$ & $124,528(143,719)$ & $124,468(143,752)$ \\
\hline & & & Median & 49,033 & 49,033 & 49,033 \\
\hline & & & Min & 3300 & 3300 & 3300 \\
\hline & & & Max & 575,698 & 575,698 & 575,698 \\
\hline & & & Skewness & 1.462 & 1.463 & 1.463 \\
\hline \multirow{5}{*}{$\begin{array}{l}\text { Lower middle- } \\
\text { income }\end{array}$} & \multirow{5}{*}{ Middle } & \multirow{5}{*}{ R 41.37} & Mean (Std. Deviation) & $167,037(173,848)$ & $167,019(173,955)$ & $167,009(173,963)$ \\
\hline & & & Median & 80,096 & 80,096 & 80,096 \\
\hline & & & Min & 3328 & 3328 & 3328 \\
\hline & & & Max & 597,087 & 597,087 & 597,087 \\
\hline & & & Skewness & .961 & .961 & .961 \\
\hline \multirow{5}{*}{$\begin{array}{l}\text { Upper middle- } \\
\text { income }\end{array}$} & \multirow{5}{*}{ Middle } & \multirow{5}{*}{ R 47.78} & Mean (Std. Deviation) & $297,129(222,083)$ & $297,061(222,107)$ & $296,861(222,240)$ \\
\hline & & & Median & 280,242 & 280,242 & 280,082 \\
\hline & & & Min & 1313 & 1313 & 1313 \\
\hline & & & Max & 694,094 & 694,094 & 694,094 \\
\hline & & & Skewness & .174 & .174 & .174 \\
\hline \multirow{5}{*}{ High-income } & \multirow{5}{*}{ High } & \multirow{5}{*}{ R 63.75} & Mean (Std. Deviation) & $250,294(205,992)$ & $249,955(206,143)$ & $249,753(206,261)$ \\
\hline & & & Median & 210,829 & 209,633 & 209,633 \\
\hline & & & Min & 2860 & 2860 & 2860 \\
\hline & & & Max & 689,557 & 689,437 & 689,437 \\
\hline & & & Skewness & .482 & .483 & .484 \\
\hline
\end{tabular}

Table 11: Accessibility by public transport. Crosstab average proximity count with regard to work locations within fixed impedance, Cape Town Metropolitan region (2010)

\begin{tabular}{|c|c|c|c|c|c|c|}
\hline $\begin{array}{c}\text { Income Category } \\
\text { Transport Zone }\end{array}$ & VOT & Impedance & Statistics & So & S1 & S2 \\
\hline \multirow{5}{*}{ Low-income } & \multirow{5}{*}{ Low } & \multirow{5}{*}{ R 38.42} & Mean (Std. Deviation) & $144,734(159,458)$ & $144,590(159,501)$ & $144,563(158,517)$ \\
\hline & & & Median & 73,106 & 72,289 & 71,479 \\
\hline & & & Min & 3592 & 3592 & 3592 \\
\hline & & & Max & 600,578 & 600,578 & 600,578 \\
\hline & & & Skewness & 1.270 & 1.270 & 1.270 \\
\hline \multirow{5}{*}{$\begin{array}{l}\text { Lower middle- } \\
\text { income }\end{array}$} & \multirow{5}{*}{ Middle } & \multirow{5}{*}{ R 41.37} & Mean (Std. Deviation) & $141,943(157,187)$ & $141,877(157,203)$ & $141,876(157,203)$ \\
\hline & & & Median & 67,029 & 67,029 & 67,029 \\
\hline & & & Min & 1991 & 1991 & 1991 \\
\hline & & & Max & 541,192 & 541,192 & 541,192 \\
\hline & & & Skewness & 1.038 & 1.038 & 1.038 \\
\hline \multirow{5}{*}{$\begin{array}{l}\text { Upper middle- } \\
\text { income }\end{array}$} & \multirow{5}{*}{ Middle } & \multirow{5}{*}{ R 47.78} & Mean (Std. Deviation) & $228,429(185,191)$ & $228,228(185,279)$ & $228,180(185,317)$ \\
\hline & & & Median & 195,951 & 195,739 & 195,739 \\
\hline & & & Min & 1230 & 1230 & 1230 \\
\hline & & & Max & 604,283 & 604,283 & 604,283 \\
\hline & & & Skewness & .357 & .358 & .358 \\
\hline \multirow{5}{*}{ High-income } & \multirow{5}{*}{ High } & \multirow{5}{*}{ R 63.75} & Mean (Std. Deviation) & $270,301(217,250)$ & $269,294(217,656)$ & $269,218(217,682)$ \\
\hline & & & Median & 235,750 & 234,538 & 234,467 \\
\hline & & & Min & 3652 & 3652 & 3652 \\
\hline & & & Max & 719,564 & 716,295 & 716,240 \\
\hline & & & Skewness & .415 & .419 & .419 \\
\hline
\end{tabular}


Table 11 shows the average number of work opportunities that can be reached by public transport within the fixed impedance. Due to the lower impedance values, in particular, low-income transport zones can reach more jobs than they could have reached by car in the same situation. The lower middle-income and upper middle-income transport zones, on the other hand, can reach on average fewer opportunities when compared to the car situation. It is likely that the value of time plays a determining role in this difference. Whereas commuters with a low VOT can travel for almost two hours with the impedances employed, commuters with a middle VOT can travel for less than an hour. The longer travel distances in terms of travel time for public transport amount to a lower number of work opportunities that can be reached. The high-income transport zones, however, seem to be in a different position in this regard. It appears that the lower generalized costs of the network in combination with a relatively high impedance value yield a higher number of work opportunities within reach.

If minibus taxis were to pay a toll, the impact on geographical accessibility seems again to be marginal. The low-income transport zones only witness a decrease of 144 ( 0.1 percent) work opportunities for S1 and 171 (0.12 percent) for S2. The high-income transport zones, on the other hand, witness a slightly higher decrease in accessibility: 1007 (S1) and 1083 (S2), 0.38 percent and 0.4 percent, respectively. With a supplementary examination of the largest decrease in S2, it was found that the worst case for the low-income transport zones was 3.964 (7 percent) and for the high-income transport zones 36.649 (26.18 percent). Once more, the spatial variability of the toll in the Cape Town metropolitan region becomes clear. Meanwhile, the outcomes indicate that the base situation is in Rawlsian terms unequal, but it appears that on average the shortest path between origin and destination does not increase that much because of a toll.

\section{$5 \quad$ Conclusion and discussion}

This paper set out to provide an ex ante insight into the equity effects of a toll charge on traffic diversion and the geographical accessibility of work locations in the Cape Town metropolitan region. In line with the expectations, the findings indicate that particularly low-income commuters divert to alternative routes; this holds for both private transport and public transport commuters. It may be concluded then that the local government's fear of this happening is therefore justified. The pricing scheme in place, however, seems to be decisive. In a low toll scenario, traffic diversions are nearly absent. This suggests that for all income categories the increase in travel speed outweighs the price of the toll and the time lost at the toll plazas. In a high toll scenario, on the other hand, mainly the high-income commuters appear to favor the toll road. In the context of Langmyhr's (1997) classification of the effects of a toll charge on an existing road network, it may therefore be argued that particularly lower middle-income commuters (in the case of private transport) and low-income commuters (in the case of public transport) can be characterized as losers.

Despite the possibility of commuters diverting to alternative routes and the immense inequity present in terms of accessibility in the base scenario, however, both the potential measures and the proximity counts do not support the hypothesis that commuters on a low income are disproportionately affected in terms of their geographical accessibility of work locations if a toll were to be implemented. In fact, in the case of the proximity count, the highest decrease in accessibility is found in a high-income transport zone. The findings show that the impact of the toll is predominantly witnessed in the transport zones situated alongside the toll roads and thus the spatial particularities of the region may be influential in this regard. Moreover, the absence of accessibility impacts may also be attributable to the static travel assignment model employed, which did not account for possible congestion effects on parallel routes as a direct consequence of traffic diverting to alternative routes.

While these outcomes do not confirm the main hypothesis, they do offer some insights into the 
spatial implications of a toll. In particular, the spatial layout of the region appears to be a decisive factor. Because South Africa is not the only developing country dealing with extreme inequalities, a thorough evaluation of the spatial configuration seems to be of foremost importance if other developing countries are to implement a toll on an existing road in an urban area. Furthermore, although it is not unlikely that the minibus taxis in the Cape Town metropolitan region will be exempt from paying the toll, the findings suggest that if they would have to pay charges it could be expected that they would divert to alternative routes. Given the dominance of informal public transport in many developing countries, it may therefore be argued that informal public transport should not be excluded from analysis.

Besides the implications of analyzing the impact a toll in the context of developing countries, both the conceptual framework and the findings show that accessibility is intimately connected to the transport system. It is therefore remarkable that so little attention has been paid to geographical accessibility measures in the context of road pricing (Tillema 2007; Condeço-Melhorado, Gutiérrez, and GarcíaPalomares 2011), whereas the incorporation of the notion of accessibility in this context can help to understand its broader implications. While the scheme developed by Langmyhr (1997) accounts for the direct effects of a toll, the incorporation of the accessibility concept suggests that these direct effects might be mediating factors within a larger daily life context.

Notwithstanding these implications, it should be emphasized that the findings of this study may be subject to at least three limitations. First, due to the modeled nature of the dataset, it was not possible to fully account for the initial pattern of travel behavior, whereas this seems to be an important variable. Second, because a static traffic assignment model was used, the possible congestion effects could not be accounted for. In addition, because of the limitation of the dataset, possible changes in destination, trip frequency, and mode choice were not taken into account either. This may explain the limited effects on geographical accessibility. The results should therefore be interpreted carefully. Third, zone-based accessibility measures were employed. However, these have been criticized in the literature. As Neutens, Schwanen, and Witlox $(2011,29)$ state: "All individuals residing within the same zone are assigned equal levels of accessibility," whereas individuals within a zone may experience complete different levels of accessibility.

Given these limitations and the theoretical and methodological suggestions, considerably more work will need to be done to fully grasp the spatial implications of a toll. In the context of the Cape Town metropolitan area, for instance, it may be wondered whether the minor accessibility impacts of a toll in the region are indeed caused by not accounting for possible congestion. A mesoscopic and dynamic traffic model may address these issues, provided that detailed information is available on the socioeconomic distribution within the transport zones and the current level of service offered by the road network. In addition, the analyses may benefit from a more detailed origin-destination matrix that takes, for instance, education and employment levels into account. It may also be worthwhile to explore the effects of the ongoing efforts by the South African government to regulate the minibus taxi industry and to see to what extent this will impact minibus taxis being exempt from paying a toll.

Also on a policy level, these considerations seem to be relevant. The expected traffic diversion may induce congestion on parallel roads; something already feared by the local government. A solution may be to reinvest the toll revenues in a more efficient public transport system. Levying a toll as part of a package solution that aims to improve the transport system as a whole can therefore be beneficial for all and might even be a serious step forward in the process toward spatial justice by tackling the present inequalities. Nevertheless, in its current form, SANRAL's plan seems to be mainly expanding road capacity for the rich private transport users with little attention given to the possible consequences for non-private vehicle owners. Given the inherent relationship between income and space in post-apartheid Cape Town, it is suggested that a toll should only be levied as part of an integrated transport plan 
that also addresses public transport provisions. Such an integrative approach will better ensure effective modal integration, an economically efficient transport system, and a network that serves spatial justice. Without an integrated land-use and transport plan in this region, a toll should maybe not be levied on the road toward spatial justice.

\section{Acknowledgments}

The authors gratefully acknowledge Utrecht University (the Netherlands) and Stellenbosch University (South Africa) for financial support. In addition, we thank the anonymous referees for their helpful comments and suggestions that enabled us to strengthen the paper. 


\section{References}

Anas, A., and R. Lindsey. 2011. Reducing urban road transportation externalities: Road pricing in theory and in practice. Review of Environmental Economics and Policy 5 (1): 66-88. doi:10.1093/ reep/req019.

Ben-Elia, E., and D. Ettema. 2011. Rewarding rush-hour avoidance: A study of commuters' travel behavior. Transportation Research Part A: Policy and Practice 45 (7): 567-582. doi: http://dx.doi. org/10.1016/j.tra.2011.03.003.

Bonsall, P., and C. Kelly. 2005. Road user charging and social exclusion: The impact of congestion charges on at-risk groups. Transport Policy 12(5): 406-418. doi:10.1016/j.tranpol.2005.06.007.

Bureau, B., and M. Glachant. 2008. Distributional effects of road pricing: Assessment of nine scenarios for Paris. Transportation Research Part A: Policy and Practice 42(7): 994-1007. doi: 10.1016/j. tra.2008.02.001.

Christman, J. 2002. Social and Political Philosophy: A Contemporary Introduction. London: Routledge.

City of Cape Town. 2010. Cape Town Traffic Model. 2001 Census-Cape Town Profile. Cape Town: Strategic Development and GIS Department.

Condeço-Melhorado, A., J. Gutiérrez, and J. C. García-Palomares. 2011. Spatial impacts of road pricing: Accessibility, regional spillovers and territorial cohesion. Transportation Research Part A: Policy and Practice 45(3): 185-203. doi:10.1016/j.tra.2010.12.003.

Cresswell, T. 2006. On the Move: Mobility in the Modern Western World. 1st ed. New York: Routledge.

De Jong, T., and J. Ritsema van Eck. 1996. Location profile-based measures as an improvement on accessibility modeling in GIS. Computers, Environment and Urban Systems 20(3): 181-190. doi:10.1016/ S0198-9715(96)00013-0.

Department of Transport. 1996. White paper on national transport policy. Pretoria, South Africa: Department of Transport.

Dimitriou, H. 2006. Urban mobility and sustainability in Asia and the power of context. Transportation Research Record 1983(1): 140-150. doi:10.3141/1983-19.

Duyvendak, J. W. 2011. Chapter 1. A homesick world? In The Politics of Home: Belonging and Nostalgia in Europe and the United States, 1st ed., 7-25. London: Palgrave Macmillan.

Ecola, L., and T. Light. 2010. Making congestion pricing equitable. Transportation Research Record 2187: 53-59. doi:10.3141/2187-08.

Eliasson, J., and M. Lundberg. 2002. Road Pricing in Urban Areas. Borlänge, Sweden: Publisher.

Eliasson, J., and L. G. Mattsson. 2006. Equity effects of congestion pricing. Transportation Research Part A: Policy and Practice 40(7): 602-620. doi:10.1016/j.tra.2005.11.002.

Elvik, R. 2009. The trade-off between efficiency and equity in road safety policy. Safety Science 47(6): 817-825. doi:10.1016/j.ssci.2008.10.012.

Finn, B. 2012. Towards large-scale flexible transport services: A practical perspective from the domain of paratransit. Research in Transportation Business and Management 3: 39-49. doi:10.1016/j. rtbm.2012.06.010.

Geurs, K. T., and J. Ritsema van Eck. 2001. Accessibility measures: Review and application. Evaluation of Accessibility Impacts of Land-Use Transport Scenarios, and Related Social and Economic Impacts. Vol. 787. Bilthoven, Netherlands: Publisher.

Geurs, K. T., and B. van Wee. 2004. Accessibility evaluation of land-use and transport strategies: Review and research directions. Journal of Transport Geography 12 (2): 127-140. doi:10.1016/j.jtrangeo.2003.10.005.

Glaister, S., and D. Graham. 2006. Proper pricing for transport infrastructure and the case of urban 
road congestion. Urban Studies 43(8): 1395-1418. doi:10.1080/00420980600776475.

Inturri, G., and M. Ignaccolo. 2011. Modeling the impact of alternative pricing policies on an urban multimodal traffic corridor. Transport Policy 18(6): 777-785. doi:10.1016/j.tranpol.2011.04.002.

Langmyhr, T. 1997. Managing equity. Transport Policy 4(1): 25-39. doi:10.1016/S0967070X(96)00031-5.

Letebele, M. O., R. C. Masemola, and M. Mokonyama. 2009. Niche public transport operational and capital investment strategies to minimize fares in the light of increased energy costs. InProceedings of the 28th Annual South African Transport Conference. Dates Held, Pretoria, South Africa.

Levinson, D. 2010. Equity effects of road pricing: A review. Transport Reviews 30(1): 33-57. doi:10.1080/01441640903189304.

Litman, T. 2011. London Congestion Pricing: Implications for Other Cities. Victoria Policy Transport Institute.

Lucas, K. 2011. Making the connections between transport disadvantage and the social exclusion of low-income populations in the Tshwane Region of South Africa. Journal of Transport Geography 19(6): 1320-1334. doi:10.1016/j.jtrangeo.2011.02.007.

Mayeres, I. 2000. The efficiency effects of transport policies in the presence of externalities and distortionary taxes. Journal of Transport Economics and Policy 34(2): 233-260.

Metrorail. 2012. Metrorail fares to increase with effect from 1 April 2012. http://www.capemetrorail. co.za/Communication/External_Communication/20120328_Media_Statement_Metrorail_fares_ to_increase_with_effect_1April2012.pdf.

Naudé, W. 2008. Is there a spatial mismatch in South Africa's metropolitan labor market? Cities 25(5): 268-276. doi:10.1016/j.cities.2008.04.004.

Neutens, T., T. Schwanen, and F. Witlox. 2011. The prism of everyday life: Toward a new research agenda for time geography. Transport Reviews 31(1): 25-47. doi:10.1080/01441647.2010.484153.

Pigou, A. C. 1920. Wealth and Welfare. London: MacMillan.

Rawls, J. 1971. An egalitarian theory of justice. In Philosophical Ethics: An Introduction to Moral Philosophy, edited by T. L. Beauchamp, 2nd ed., 365-370. New York, NY: McGraw Hill.

Republic of South Africa. 2008. Declaration of N1-N2 Winelands Toll Highway: National Road N1, Bellville (R300 Interchange), to Sandhills and National Road N2, Swartklip (R300 Interchange) to Bot River as Toll Roads. Act. No. 978. Government Gazette 519 (31422), September 31. Pretoria, South Africa.

Republic of South Africa. 2012b. Draft Regulations on Exemptions from the Payments of Tolls 2012: Publication for Comment. Notice 803 of 2012. Government Gazette. 569 (35755), November 2. Pretoria, South Africa.

Republic of South Africa. 2012a. Gauteng Freeway Improvement Project, Toll Roads: Publication of the Tariffs for the Different Categories of Road Users and Classes of Motor Vehicles. Notice 801 of 2012. Government Gazette 569 (35756), November 2. Pretoria, South Africa.

Republic of South Africa. 1998. The South African National Roads Agency Limited and National Roads. Act. No. 470. Government Gazette 93 (18789), March 31. Cape Town, South Africa.

Rich, J., and O. A. Nielsen. 2007. A socio-economic assessment of proposed road user charging schemes in Copenhagen. Transport Policy 14(4): 330-345. doi:10.1016/j.tranpol.2007.03.003.

Rouwendal, J., and E. T. Verhoef. 2006. Basic economic principles of road pricing: From theory to applications. Transport Policy 13(2): 106-114. doi:10.1016/j.tranpol.2005.11.007.

SANRAL. 2012. A User Guide to Tolling. Pretoria, South Africa: SANRAL. www.nra.co/za/content/A Guide_To_Tolling.pdf.

Santos, G., and L. Rojey. 2004. Distributional impacts of road pricing: The truth behind the myth. Transportation 31(1): 21-42. doi:10.1023/B:PORT.0000007234.98158.6b. 
Smith, D. M. 1994. Geography and Social Justice. Oxford: Blackwell Publishing Ltd.

Standish, B. 2008. The Economic Impact of the Proposed Winelands Toll Road Project. http://sanral.ensightcdn.com/content/EconomicUpdateN1N26Ma y2008.pdf.

Taylor, B. D., and A. T. Norton. 2009. Paying for transportation: What's a fair price? Journal of Planning Literature 24(1): 22-36. doi:10.1177/0885412209347156.

Teubel, U., 2000. The welfare effects and distributional impact of road user charges on commuters—an empirical analysis of Dresden. International Journal of Transport Economics 27(2): 231-254.

The World Bank. 2002. Cities on the Move. A World Bank Urban Transport Strategy Review. Washington DC: The World Bank.

Tillema, T. 2007. Road Pricing: A Transport Geographical Perspective. Geographical Accessibility and Short and Long-Term Behavioral Effects. Utrecht, Netherlands: Utrecht University.

Tillema, T., T. de Jong, B. van Wee, and D. van Amelsfort. 2008. Sensitivity of geographical accessibility measures under road-pricing conditions. In Pricing in Road Transport. A Multi-Disciplinary Perspective, edited by E. Verhoef, M. Bliemer, and B. van Wee, 227-249. Bodmin, Cornwall, UK: MPG Books Ltd.

Tillema, T., E. Verhoef, B. van Wee, and D. van Amelsfort. 2011. Evaluating the effects of urban congestion pricing: Geographical accessibility versus social surplus. Transportation Planning and Technology 34(7): 669-689.

Van Wee, B., and K. Lucas. 2012. Evaluating transport options in order to curb social exclusion: The importance of ethical theories and accessibility. Tijdschrift Vervoerswetenschap 48(1): 52-64.

Vickrey, W. S. 1969. Congestion theory and transport investment. The American Economic Review 59(3): 251-260. doi: 10.1126/science.151.3712.867-a.

Walters, J. 2008. Overview of public transport policy developments in South Africa. Research in Transportation Economics 22(1): 98-108. doi: 10.1016/j.retrec.2008.05.023. 